\title{
Using CO2:CO Correlations to Improve Inverse Analyses of Carbon Fluxes
}

\section{Citation}

Palmer, Paul I., Parvadha Suntharalingham, Dylan B. A. Jones, Daniel J. Jacob, David G. Streets, Qingyan Fu, Stephanie A. Vay, Glen W. Sachse. 2006. Using C02:CO correlations to improve inverse analyses of carbon fluxes. Journal of Geophysical Research 111: D12318.

\section{Published Version}

doi:10.1029/2005JD006697

\section{Permanent link}

http://nrs.harvard.edu/urn-3:HUL.InstRepos:3743789

\section{Terms of Use}

This article was downloaded from Harvard University's DASH repository, and is made available under the terms and conditions applicable to Other Posted Material, as set forth at http:// nrs.harvard.edu/urn-3:HUL.InstRepos:dash.current.terms-of-use\#LAA

\section{Share Your Story}

The Harvard community has made this article openly available.

Please share how this access benefits you. Submit a story.

\section{Accessibility}




\title{
Using $\mathrm{CO}_{2}$ : $\mathrm{CO}$ correlations to improve inverse analyses of carbon fluxes
}

\author{
Paul I. Palmer, ${ }^{1,2}$ Parvadha Suntharalingam, ${ }^{1}$ Dylan B. A. Jones, ${ }^{1,3}$ Daniel J. Jacob, ${ }^{1}$ \\ David G. Streets, ${ }^{4}$ Qingyan Fu, ${ }^{5}$ Stephanie A. Vay, ${ }^{6}$ and Glen W. Sachse ${ }^{6}$ \\ Received 22 September 2005; revised 2 February 2006; accepted 20 March 2006; published 30 June 2006.
}

[1] Observed correlations between atmospheric concentrations of $\mathrm{CO}_{2}$ and $\mathrm{CO}$ represent potentially powerful information for improving $\mathrm{CO}_{2}$ surface flux estimates through coupled $\mathrm{CO}_{2}-\mathrm{CO}$ inverse analyses. We explore the value of these correlations in improving estimates of regional $\mathrm{CO}_{2}$ fluxes in east Asia by using aircraft observations of $\mathrm{CO}_{2}$ and $\mathrm{CO}$ from the TRACE-P campaign over the NW Pacific in March 2001. Our inverse model uses regional $\mathrm{CO}_{2}$ and $\mathrm{CO}$ surface fluxes as the state vector, separating biospheric and combustion contributions to $\mathrm{CO}_{2} \cdot \mathrm{CO}_{2}-\mathrm{CO}$ error correlation coefficients are included in the inversion as off-diagonal entries in the a priori and observation error covariance matrices. We derive error correlations in a priori combustion source estimates of $\mathrm{CO}_{2}$ and $\mathrm{CO}$ by propagating error estimates of fuel consumption rates and emission factors. However, we find that these correlations are weak because $\mathrm{CO}$ source uncertainties are mostly determined by emission factors. Observed correlations between atmospheric $\mathrm{CO}_{2}$ and $\mathrm{CO}$ concentrations imply corresponding error correlations in the chemical transport model used as the forward model for the inversion. These error correlations in excess of 0.7 , as derived from the TRACE-P data, enable a coupled $\mathrm{CO}_{2}$ $\mathrm{CO}$ inversion to achieve significant improvement over a $\mathrm{CO}_{2}$-only inversion for quantifying regional fluxes of $\mathrm{CO}_{2}$.

Citation: Palmer, P. I., P. Suntharalingam, D. B. A. Jones, D. J. Jacob, D. G. Streets, Q. Fu, S. A. Vay, and G. W. Sachse (2006), Using $\mathrm{CO}_{2}$ : $\mathrm{CO}$ correlations to improve inverse analyses of carbon fluxes, J. Geophys. Res., 111, D12318, doi:10.1029/2005JD006697.

\section{Introduction}

[2] Measurements of atmospheric composition provide powerful constraints to improve understanding of surface fluxes of trace compounds and their subsequent fate in the atmosphere. Recent studies have exploited these data by employing an inverse model approach [Bousquet et al., 1999; Gilliland et al., 2003; Palmer et al., 2003], in which a chemical transport model (forward model) is used to relate the sensitivity of an observed chemical concentration measurement to changes in particular model parameters (e.g., surface fluxes). An optimal estimation inverse model then combines this sensitivity information with the observations to yield the solution that is most consistent with the observations, the a priori information about the model parameters, and their relative errors. Estimated error vari-

\footnotetext{
${ }^{1}$ Division of Engineering and Applied Sciences, Harvard University, Cambridge, Massachusetts, USA.

${ }^{2}$ Now at School of Earth and Environment, University of Leeds, Leeds, $\mathrm{UK}$.

${ }^{3}$ Now at Department of Physics, University of Toronto, Toronto, Ontario, Canada.

${ }^{4}$ Argonne National Laboratory, Argonne, Illinois, USA.

${ }^{5}$ Shanghai Environmental Monitoring Center, Shanghai, China.

${ }^{6}$ NASA Langley Research Center, Hampton, Virginia, USA.

Copyright 2006 by the American Geophysical Union. 0148-0227/06/2005JD006697\$09.00
}

ance and covariance information is included in the inversion via the a priori and observation error covariance matrices. Previous studies that analyzed correlations between different trace gases [e.g., Ciais et al., 1995; Enting et al., 1995] did not take advantage of these additional correlations in inverse model analyses. These correlations can arise from having similar spatial and temporal flux distributions, from chemical mass balance, or from atmospheric transport processes. Exploitation of these correlations in an inverse model involves quantifying the associated error correlation coefficients to include in the off-diagonal entries to the a priori and observation error covariance matrices.

[3] We present in this paper a method to objectively quantify error correlations between $\mathrm{CO}$ and $\mathrm{CO}_{2}$ as constraints in inverse model calculations for the budgets of both gases. Carbon dioxide over continents is released by combustion and biospheric respiration, and is taken up by photosynthesis. Over many regions of the world these combustion and biogenic fluxes overlap significantly. Separation of these fluxes in inverse analyses of $\mathrm{CO}_{2}$ observations can therefore be difficult. Combustion is a source of $\mathrm{CO}$ and $\mathrm{CO}_{2}$, with the $\mathrm{CO}$ emission ratio decreasing with combustion efficiency. Biospheric fluxes of $\mathrm{CO}$ are small. Here we use the error correlation coefficients between $\mathrm{CO}$ and $\mathrm{CO}_{2}$ in an inverse model analysis to estimate simultaneously $\mathrm{CO}$ and $\mathrm{CO}_{2}$ fluxes with the principal purpose of reducing uncertainty of combustion and biospheric $\mathrm{CO}_{2}$ 


\section{$\mathrm{CO}[\mathrm{ppb}] \quad 0-2 \mathrm{~km} \quad \mathrm{CO}_{2}[\mathrm{ppm}]$}
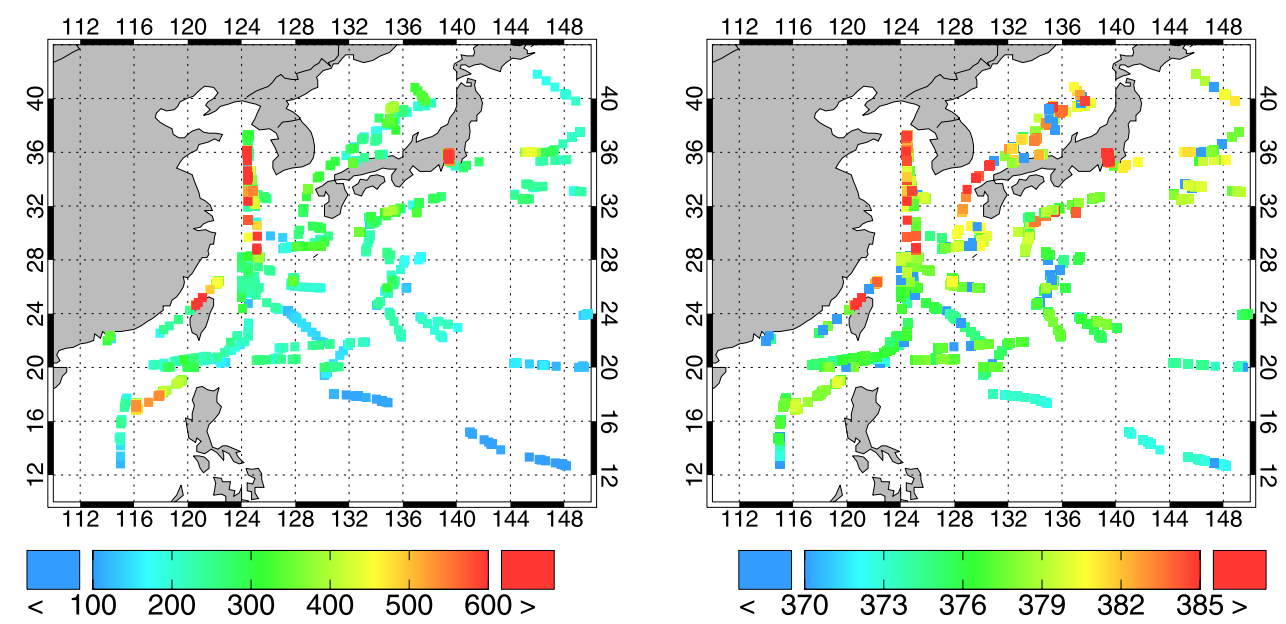

Figure 1. Mean $\mathrm{CO}$ and $\mathrm{CO}_{2}$ boundary layer $(0-2 \mathrm{~km})$ concentrations during the TRACE-P aircraft mission in March-April 2001 [Jacob et al., 2003]. The data are averaged on the GEOS-CHEM $2^{\circ} \times 2.5^{\circ}$ model grid.

flux estimates. We apply this method to $\mathrm{CO}$ and $\mathrm{CO}_{2}$ concentration data from the NASA TRACE-P aircraft campaign [Jacob et al., 2003], conducted over the western Pacific during February-April 2001. Two aircraft (DC8 and $\mathrm{P} 3 \mathrm{~B}$ ) were used during TRACE-P to sample Asian outflow between $10^{\circ}$ and $45^{\circ} \mathrm{N}$ and 0 and $12 \mathrm{~km}$ altitude. TRACE-P was conducted during the season of strongest outflow from mainland Asia to the Pacific, driven by frequent midlatitude cyclones and associated cold fronts and warm conveyor belts [Liu et al., 2003]. The FebruaryApril period is also the biomass burning season in Southeast Asia [Heald et al., 2003].

[4] Recent studies have used observed $\mathrm{CO}_{2}: \mathrm{CO}$ slopes derived from linear regression of atmospheric composition data to identify the source origins of air masses sampled in TRACE-P [Suntharalingam et al., 2004; Takegawa et al., 2004]. Suntharalingam et al. [2004] showed strong correlations between $\mathrm{CO}_{2}$ and $\mathrm{CO}$ concentrations during TRACE-P with distinct $\mathrm{CO}_{2}$ : $\mathrm{CO}$ slopes that they used to constrain regional flux estimates of $\mathrm{CO}_{2}$. They interpreted the $\mathrm{CO}_{2}$ : $\mathrm{CO}$ correlations using the GEOS-CHEM chemical transport model (Appendix A) and identified a large underestimate in the Chinese biospheric $\mathrm{CO}_{2}$ flux. Other TRACE-P studies have used CO observations with success to constrain east Asian source estimates of CO [Carmichael et al., 2003; Palmer et al., 2003; Allen et al., 2004; Heald et al., 2004; Tan et al., 2004], but without consideration of the implications for $\mathrm{CO}_{2}$ surface fluxes.

\section{Correlations Between $\mathrm{CO}$ and $\mathrm{CO}_{2}$ Errors}

[5] There are two types of $\mathrm{CO}_{2}: \mathrm{CO}$ correlations that can serve as error covariance constraints for a joint $\mathrm{CO}_{2}: \mathrm{CO}$ inverse analysis. Correlations between $\mathrm{CO}_{2}$ and $\mathrm{CO}$ combustion sources provide a constraint on the a priori fluxes used for the joint inversion. Observed correlations between atmospheric $\mathrm{CO}_{2}$ and $\mathrm{CO}$ concentrations imply corresponding correlations in the source-receptor relation- ships determining the concentrations at the observation points, i.e., in the forward model for the inversion. Therefore they provide information on model error correlations for the observation error covariance matrix. Here we derive these two types of error correlation for the Asian outflow conditions sampled by the TRACE-P mission.

\subsection{Observation Error Correlations}

[6] Atmospheric transport processes during TRACE-P moved air masses laden with $\mathrm{CO}$ and $\mathrm{CO}_{2}$ from east Asia over the Pacific [Liu et al., 2003; Fuelberg et al., 2003], introducing correlation in the $\mathrm{CO}$ and $\mathrm{CO}_{2}$ concentrations. TRACE-P took place before the onset of the growing season, hence the correlations are positive. Figure 1 illustrates the spatial distribution of TRACE-P CO and $\mathrm{CO}_{2}$ concentration data in the boundary layer. Examination of the spatial distributions reveal strong regional correlations for individual flights (correlation coefficients $>0.8$ ) with $\mathrm{CO}_{2}$ :CO slopes ranging from $10 \mathrm{~mol} / \mathrm{mol}$ in biomass burning outflow from Southeast Asia, to $20-30 \mathrm{~mol} / \mathrm{mol}$ in Chinese pollution plumes and $50 \mathrm{~mol} / \mathrm{mol}$ in outflow from Japan [Suntharalingam et al., 2004; Takegawa et al., 2004]. TRACE-P sampled relatively fresh air masses (12 days old) so we can assume that loss of $\mathrm{CO}$ by reaction with $\mathrm{OH}$ does not affect the $\mathrm{CO}_{2}$ : $\mathrm{CO}$ correlation driven by Asian outflow.

[7] Figure 2 shows correlation coefficients between $\mathrm{CO}$ and $\mathrm{CO}_{2}$ concentrations measured during TRACE-P as a function of altitude and latitude. These correlation coefficients are typically $>0.7$, and vary only by $5-10 \%$ as a function or altitude, with smaller values at higher altitudes where aged air masses originating from regions outside Asia play a relatively large contribution to the total $\mathrm{CO}$ abundances. It is useful to split the TRACE-P data into two distinct latitudinal regions, characterized by differences in sampled air masses [Blake et al., 2003]. North of $30^{\circ} \mathrm{N}$, air masses were heavily influenced by fossil fuel and biofuel emissions from China, Korea and Japan, with essentially no 


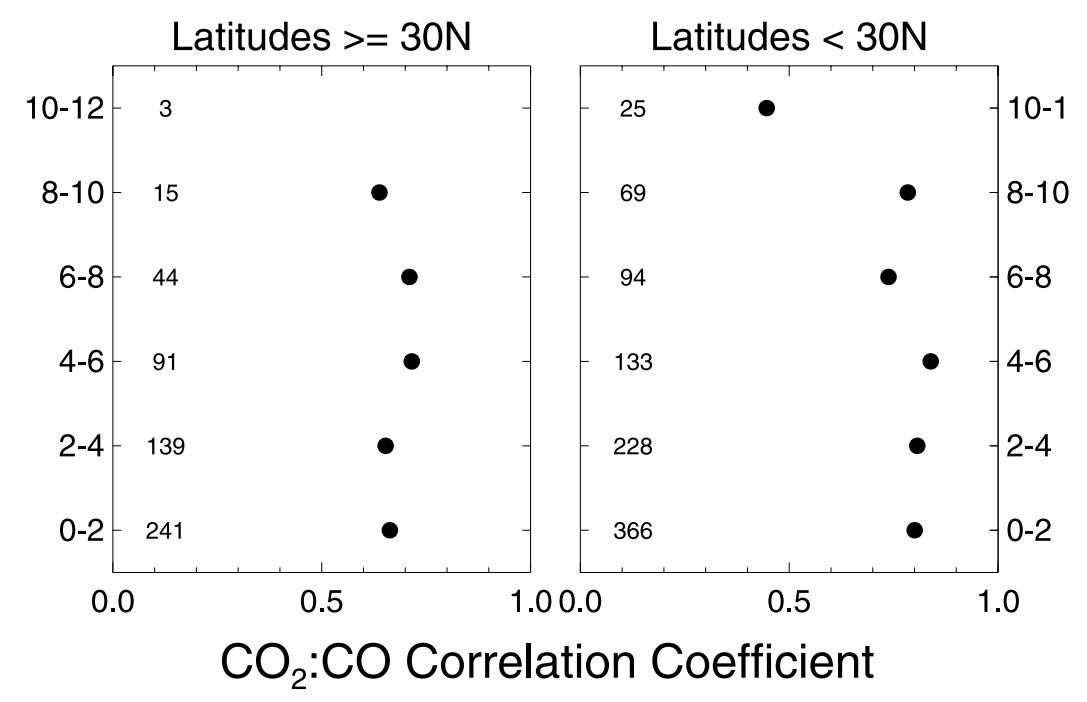

Figure 2. Correlation coefficients $(r)$ between $\mathrm{CO}$ and $\mathrm{CO}_{2}$ mixing ratios measured during TRACE-P as a function of altitude $(2-\mathrm{km}$ altitude bins). Numbers inset in each plot refer to the number of observations used to compute the correlation at each altitude bin. Correlation coefficients calculated from 10 or more data points are shown.

influence from biomass burning [Liu et al., 2003]. South of $30^{\circ} \mathrm{N}$, and particularly in the free troposphere, air masses were strongly influenced by biomass burning from Southeast Asia. Correlation coefficients are larger at latitudes $<30^{\circ} \mathrm{N}$ (Figure 2) because background concentrations are lower and less variable (Figure 1).

\subsection{Source Error Correlations}

[8] Combustion is a source of both $\mathrm{CO}$ and $\mathrm{CO}_{2}$, and consequently introduces a correlation in emissions. We take advantage of a detailed fuel emission inventory for east Asia [Streets et al., 2003] that offers an opportunity to quantify the source error correlation by providing uncertainty estimates for the sources from individual energy sectors. We do not consider error correlation for the biomass burning source, and as we will see this is justified because of large uncertainty in the $\mathrm{CO}$ emission factor.

[9] The emission of a gas from a combustion process ( $\mathrm{g}$ gas emitted $\mathrm{yr}^{-1}$ ) can be described as a product of the activity rate $A$ ( $\mathrm{g}$ fuel burned $\mathrm{yr}^{-1}$ ) and the emission factor $F$ (g gas emitted per $g$ fuel burned). Activity rates are obtained from energy statistics. Emission factors are determined from laboratory test burns or field measurements. The activity rates and emission factors are both subject to uncertainties. Emission factors for $\mathrm{CO}_{2}$ and $\mathrm{CO}$ vary with the combustion process. For example, Chinese $\mathrm{CO}$ emission factors range from $0.7 \mathrm{Gg} / \mathrm{PJ}$ for industrial coal burning to $7.0 \mathrm{Gg} / \mathrm{PJ}$ for gasoline-powered cars [Streets et al., 2003]. Chinese $\mathrm{CO}_{2}$ emission factors for the same processes are $24.7 \mathrm{Gg} / \mathrm{PJ}$ and $20 \mathrm{Gg} / \mathrm{PJ}$, respectively [Streets et al., 2003]. Even for inefficient forms of combustion, e.g., open biomass burning, values of $F$ for $\mathrm{CO}_{2}$ are an order of magnitude greater than for $\mathrm{CO}$ [Andreae and Merlet, 2001]. The sum of $\mathrm{CO}$ and $\mathrm{CO}_{2}$ typically represents $>95 \%$ of the total emitted carbon, with $\mathrm{CH}_{4}$, and nonmethane volatile organic compounds (NMVOC) contributing the remaining few percent [Streets et al., 2003].
[10] Correlation between $\mathrm{CO}$ and $\mathrm{CO}_{2}$ emissions can be introduced via $A$ or $F$. We assume activity rates are common to both gases, while $\mathrm{CO}$ and $\mathrm{CO}_{2}$ emission factors are inversely correlated. We use the east Asian emission inventory for 2000 from Streets et al. [2003], which includes information about $A, F$, and associated $1 \sigma$ uncertainties $(\Delta)$ for different energy sectors and for individual regions. The inventory includes sector emissions from industry (coal and oil), domestic biofuel, and transportation (domestic and commercial, gas and diesel powered, vehicles). We derive error correlations for the national inventories, summing over all sectors and over all regions within a country.

[11] Table 1 presents values of $\Delta A$ and $\Delta F$, expressed as a percentage of $A$ and $F$, from Streets et al. [2003] for individual east Asian countries. $\mathrm{CO}$ emission estimates are the most uncertain, due to the uncertainty of the emission factors. The most uncertain emission estimates are from biofuels, reflecting large uncertainties in both $F$ and $A$.

[12] We use a Monte Carlo approach to estimate error correlations between $\mathrm{CO}$ and $\mathrm{CO}_{2}$ sources for individual countries, in which we generate a large ensemble of $\mathrm{CO}$ and $\mathrm{CO}_{2}$ emissions $E_{i}$ for each energy sector $i$ within each country by perturbing the mean values for $A^{i}$ and $F^{i}$ by their estimated $1 \sigma$ uncertainties, $\Delta A^{i}$ and $\Delta F^{i}$, and a population of normally distributed random numbers $\epsilon^{i}$ with unit variance (equation set (1)):

$$
\begin{aligned}
& E_{\mathrm{CO}_{2}}^{i}=\left(A^{i}+\epsilon_{A}^{i} \Delta A^{i}\right)\left(F_{\mathrm{CO}_{2}}^{i}+\epsilon_{\mathrm{CO}_{2}}^{i} \Delta F_{\mathrm{CO}_{2}}^{i}\right) \\
& E_{\mathrm{CO}}^{i}=\left(A^{i}+\epsilon_{A}^{i} \Delta A^{i}\right)\left(F_{C O}^{i}+\epsilon_{C O}^{i} \Delta F_{C O}^{i}\right)
\end{aligned}
$$

[13] Regional $\mathrm{CO}_{2}: \mathrm{CO}$ error correlations are calculated by first summing the ensembles of $\mathrm{CO}$ and $\mathrm{CO}_{2}$ emissions generated using the Monte Carlo approach from different energy sectors within a particular country. For each energy sector $i$ within a particular country we generate an ensemble of size $10^{4}$, ensuring a statistical significant correlation. In the absence of a regional and sector breakdown of $\mathrm{CH}_{4}$ and 
Table 1. Percentage Uncertainties of Activity Rates $(\Delta A / A)$ and Emission Factors $(\Delta F / F)$ Associated With East Asian $\mathrm{CO}$ and $\mathrm{CO}_{2}$ Emissions From Fuel Consumption

\begin{tabular}{|c|c|c|c|c|c|c|c|c|c|}
\hline \multirow[b]{3}{*}{ Region } & \multicolumn{4}{|c|}{ Biofuel } & \multicolumn{4}{|c|}{ Fossil Fuel $^{\mathrm{a}}$} & \multirow{3}{*}{$\begin{array}{l}\mathrm{CO}_{2}: \mathrm{CO} \text { Source } \\
\text { Error Correlation } \\
\end{array}$} \\
\hline & \multicolumn{2}{|c|}{$\mathrm{CO}$} & \multicolumn{2}{|c|}{$\mathrm{CO}_{2}$} & \multicolumn{2}{|c|}{$\mathrm{CO}$} & \multicolumn{2}{|c|}{$\mathrm{CO}_{2}$} & \\
\hline & $\Delta A / A$ & $\Delta F / F$ & $\Delta A / A$ & $\Delta F / F$ & $\Delta A / A$ & $\Delta F / F$ & $\Delta A / A$ & $\Delta F / F$ & \\
\hline China & 25 & 240 & 20 & 6 & 12 & 67 & 7 & 7 & 0.03 \\
\hline Korea & 25 & 240 & 20 & 6 & 8 & 65 & 5 & 6 & 0.04 \\
\hline Japan & 18 & 240 & 15 & 6 & 8 & 24 & 5 & 9 & -0.46 \\
\hline Southeast Asiab & 36 & 240 & 30 & 6 & 31 & 121 & 10 & 9 & 0.17 \\
\hline
\end{tabular}

${ }^{\mathrm{a}} \mathrm{CO}$ and $\mathrm{CO}_{2}$ sectors include domestic coal, domestic oil, industrial coal, and transport [Streets et al., 2003]. Values of $\Delta A$ and $\Delta F$ given here are national averages (Figure 4) weighted by activity rates over different sectors and regions resolved by Streets et al. [2003].

${ }^{\mathrm{b}} \mathrm{SEA}$ in Figure 4.

other VOC emission factors, we assume that $\mathrm{CO}_{2}$ and $\mathrm{CO}$ represents $97.5 \%$ of the total carbon emitted [Streets et al., 2003], and that $\mathrm{CH}_{4}$ and other VOCs contribute the remaining $2.5 \%$. In perturbations to this best estimate we require that the sum of the $\mathrm{CO}_{2}$ and $\mathrm{CO}$ emission factors is between $95 \%$ and $100 \%$, ensuring that we only consider physically realistic realizations, e.g., the total carbon emitted does not exceed the carbon content of the fuel burned.

[14] The value of the $\mathrm{CO}_{2}: \mathrm{CO}$ error correlation for a particular sector $i$ depends on the relative uncertainties associated with $A^{i}$ and $F^{i}$. In the limiting case, where values of $F^{i}$ are known perfectly the correlation will be +1 because $\Delta A$ is common to both $\mathrm{CO}$ and $\mathrm{CO}_{2}$. Conversely, if $A^{i}$ is known perfectly, uncertainties in $F^{i}$ will lead to correlation coefficients between -1 and +1 . In practice, there are significant uncertainties associated with both $A^{i}$ and $F^{i}$, and error correlations between $\mathrm{CO}_{2}$ and $\mathrm{CO}$ sources represent a balance between the relative magnitudes and uncertainties of $A^{i}$ and $F^{i}$, e.g., $F_{\mathrm{CO}_{2}}{ }^{i}$ is a smaller factor of variability for $\mathrm{CO}_{2}$ emission than the activity rate, while the converse holds for $\mathrm{CO}$.

[15] We find that the error correlations on the a priori sources of $\mathrm{CO}_{2}$ and $\mathrm{CO}$, corresponding to values of $\Delta A^{i}$ and $\Delta F^{i}$ prescribed by Streets et al. [2003], are negligible or weakly negative (Table 1 ). This is due primarily to large values of $\Delta F_{C O}^{i}$. However, analyses of the TRACE-P CO data indicate that the Streets et al. [2003] inventory under- estimated $A$ and $F$ [Tan et al., 2004], so we explored the sensitivity of the $\mathrm{CO}_{2}$ : $\mathrm{CO}$ source error correlation to the range of possible values of $\Delta A^{i}$ and $\Delta F^{i}$ (Figure 3) using the same percentage change in $\Delta A^{i}$ and $\Delta F^{i}$ over all sectors $i$ and over all regions. As we will show later, source error correlation coefficients need to be greater than 0.5 before we get a significant improvement in the inverse analysis for $\mathrm{CO}_{2}$ fluxes. Such correlations are unrealistic, given constraints on $A$ from the $\mathrm{CO}_{2}$ concentrations [Suntharalingam et al., 2004].

\section{Inverse Model}

[16] Our inverse model aims to achieve the best estimate of $\mathrm{CO}$ and $\mathrm{CO}_{2}$ fluxes that is consistent with the TRACE-P concentration measurements of $\mathrm{CO}$ and $\mathrm{CO}_{2}$, the a priori $\mathrm{CO}$ and $\mathrm{CO}_{2}$ flux estimates, and their respective uncertainties. It builds on our previous CO-only inverse model that used the TRACE-P observations to estimate east Asian CO fluxes [Palmer et al., 2003].

\subsection{Model Description}

[17] Anthropogenic sources of $\mathrm{CO}$ and $\mathrm{CO}_{2}$ include burning of fossil fuels and biofuels, and biomass burning (Tables 2 and 3). We use a priori anthropogenic emission estimates of $\mathrm{CO}$ and $\mathrm{CO}_{2}$ from Streets et al. [2003] for east Asia and from Palmer et al. [2003] and Suntharalingam et
CHINA+TAIWAN

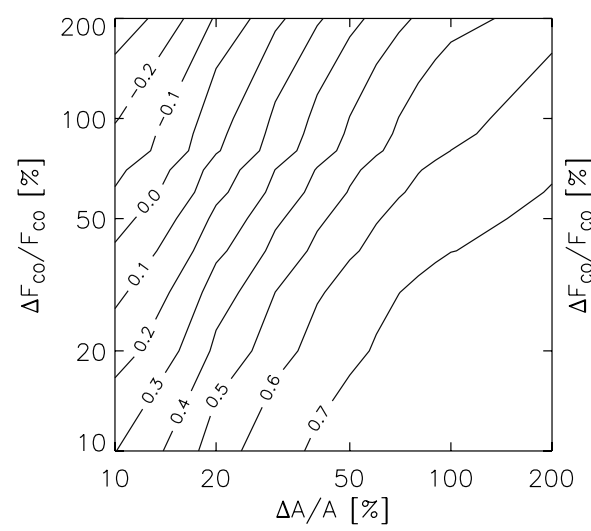

JAPAN+KOREA

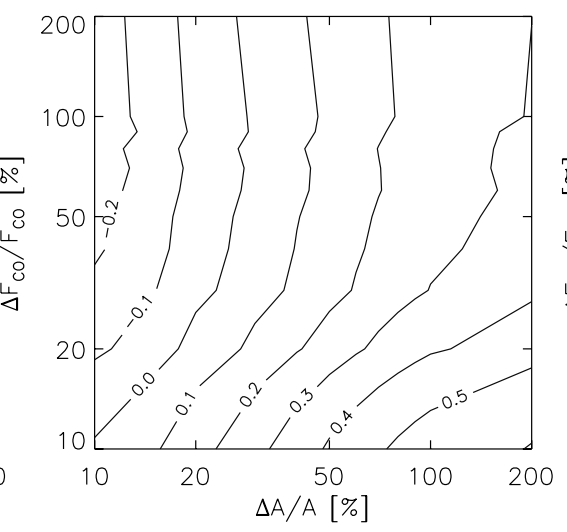

SOUTHEAST ASIA

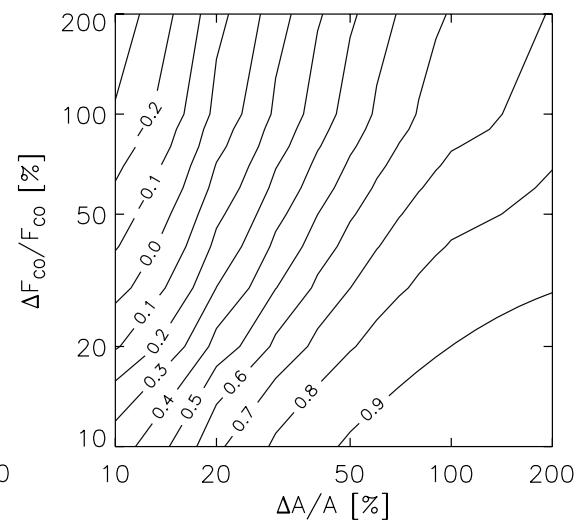

Figure 3. Regional error correlation coefficients $r$ between bottom-up emission estimates for $\mathrm{CO}_{2}$ and $\mathrm{CO}$ from fuel consumption as a function of relative uncertainties in activity rates $A$ and emission factors $F$. These illustrative calculations assume the same relative uncertainties for all energy sectors within the region. 
Table 2. A Priori Sources of CO for the Inverse Model Analysis

\begin{tabular}{|c|c|c|c|c|}
\hline Region & $\begin{array}{c}\text { Biofuels (BF), } \\
\text { Tg CO } \mathrm{yr}^{-1}\end{array}$ & $\begin{array}{c}\text { Fossil Fuels (FF), } \\
\text { Tg CO yr }\end{array}$ & $\begin{array}{c}\text { Biomass Burning (BB), } \\
\text { Tg CO yr }\end{array}$ & $\begin{array}{c}\text { Global } \mathrm{CH}_{4} \text { and } \\
\text { Biogenic } \mathrm{NMVOCs} \text {, } \\
\text { Tg CO yr }\end{array}$ \\
\hline China $(\mathrm{CH})$ & $49 \pm 38$ & $59 \pm 46$ & $18 \pm 9$ & - \\
\hline Korea (KR) & $3 \pm 1$ & $3 \pm 1$ & $0.08 \pm 0.04$ & - \\
\hline Japan (JP) & $3 \pm 1$ & $6 \pm 1$ & $0.3 \pm 0.1$ & - \\
\hline Southeast Asia (SEA) & $23 \pm 23$ & $10 \pm 10$ & $81 \pm 40$ & - \\
\hline Boreal Asia (BA) & - & - & $12 \pm 6$ & - \\
\hline Rest of world (ROW) & $124 \pm 26$ & $301 \pm 78$ & $396 \pm 198$ & $1205 \pm 301$ \\
\hline
\end{tabular}

${ }^{\text {a }}$ Sources from BF, BB, and FF include the secondary source of CO from the oxidation of NMVOCs coemitted with CO.

al. [2004] for the rest of the world (ROW). We use the same biomass burning emission estimates as Palmer et al. [2003], based on daily satellite fire count data for the TRACE-P period [Heald et al., 2003]. We account for the secondary source $\mathrm{CO}$ from oxidation of anthropogenic VOCs coemitted with CO by scaling up fossil fuel and biofuel (19\%) and biomass burning (16\%) [Heald et al., 2004]; these scaling factors are different from those used by Palmer et al. [2003] and are reflected in the a priori emissions presented in Table 2. The ROW represents a background of $\mathrm{CO}$ and $\mathrm{CO}_{2}$, including sources outside of Asia and chemical production of $\mathrm{CO}$ from $\mathrm{CH}_{4}$. ROW also includes the chemical production of $\mathrm{CO}$ from biogenic NMVOCs, representing a small diffuse source over the TRACE-P period (which was mainly outside the growing season). Daily mean terrestrial biosphere fluxes of $\mathrm{CO}_{2}$ are provided by the CASA balanced biosphere model [Randerson et al., 1997]. TRACE-P data are a few days downwind of continental sources and at this offshore distance the influence of diurnal variation from the terrestrial biosphere is weak [Suntharalingam et al., 2004]. For the TRACE-P season (March) there is a net positive flux of $\mathrm{CO}_{2}$ from the east Asian biosphere [Suntharalingam et al., 2004]. Ocean $\mathrm{CO}_{2}$ fluxes, prescribed by Takahashi [1999], are assumed not to contribute significantly to the magnitude and variability of TRACE-P data [Suntharalingam et al., 2004]. We aggregate the $\mathrm{CO}_{2}$ flux from the global ocean with ROW.

[18] Observed $\mathrm{CO}$ and $\mathrm{CO}_{2}$ mixing ratios (measurement vector $\mathbf{y}$ ) are related to $\mathrm{CO}$ and $\mathrm{CO}_{2}$ surface fluxes (state vector $\mathbf{x}$ ) by

$$
\mathbf{y}=\mathbf{K} \mathbf{x}+\epsilon
$$

where $\mathbf{K}$ is the Jacobian matrix describing the forward model sensitivity. We use the GEOS-CHEM CTM as the forward model. Loss of $\mathrm{CO}$ is computed with fixed 3-D $\mathrm{OH}$ fields from GEOS-CHEM to enforce linearity as described by equation (2). The linearized $\mathrm{CO}$ and linear
$\mathrm{CO}_{2}$ models allow us to describe total $\mathrm{CO}$ and $\mathrm{CO}_{2}$ model concentrations as a linear sum of contributions from different countries and different sources.

[19] The state vector $\mathbf{x}$ comprises annual mean $\mathrm{CO}$ and $\mathrm{CO}_{2}$ anthropogenic (including biomass burning) source estimates assuming seasonal variations [Duncan et al., 2003; Streets et al., 2003]. It also includes $\mathrm{CO}_{2}$ biospheric surface fluxes for March 2001 from the different geopolitical regions of Figure 4.

[20] The state vector components were chosen on the ability of the TRACE-P data to independently resolve source regions (Figure 4) and processes (fuel FL and biomass burning BB), as derived formally by Palmer et al. [2003] and Heald et al. [2004]. For CO we use six components: CHFL, KRJP, SEA, CHBB, BABB, and ROW. For $\mathrm{CO}_{2}$ we add regional biospheric terms (BS) and use eight components: CHFL, KRJP, CHBB, BABB, ROW, CHBS, KRJPBS, BABS. Observed $\mathrm{CO}_{2}$ signatures for biomass burning from China (CHBB), boreal Asia (BABB), and for SEA are too weak to be resolved independently.

[21] The measurement vector $\mathbf{y}$ consists of the TRACE-P $\mathrm{CO}$ and $\mathrm{CO}_{2}$ mixing ratio data. $\mathrm{CO}$ and $\mathrm{CO}_{2}$ mixing ratios are measured using a differential absorption tunable diode laser system [Sachse et al., 1987] and a nondispersive infrared analyzer [Vay et al., 2003], respectively. The data used for the inversion includes 299 hours of measurements from the two aircraft over 28 flights between 27 February and 3 April, 2001. We use the data for individual flights averaged on the GEOS-CHEM $2^{\circ} \times 2.5^{\circ}$ model grid.

[22] Errors associated with $\mathbf{K}$ and $\mathbf{y}$ (the sum of which is described by $\epsilon$ ), include measurement accuracy, subgrid variability of observations (representation error), and model error. The ensemble characteristics of these errors are described by the observation error covariance, $\mathbf{S}_{\Sigma}$, representing a sum of the covariance matrices from individual sources of error. This will be discussed further in the next section.

Table 3. A Priori Surface Fluxes of $\mathrm{CO}_{2}$ for the Inverse Model Analysis

\begin{tabular}{lccccc}
\hline \multicolumn{1}{c}{ Region } & $\begin{array}{c}\text { Biofuels, } \\
\mathrm{Tg} \mathrm{CO}_{2} \mathrm{yr}^{-1}\end{array}$ & $\begin{array}{c}\text { Fossil Fuels, } \\
\mathrm{Tg} \mathrm{CO}_{2} \mathrm{yr}^{-1}\end{array}$ & $\begin{array}{c}\text { Biomass Burning, } \\
\mathrm{Tg} \mathrm{CO}_{2} \mathrm{yr}^{-1}\end{array}$ & $\begin{array}{c}\text { Terrestrial Biosphere, } \\
\mathrm{Tg} \mathrm{CO}_{2} / \mathrm{March} \mathrm{2001}^{\text {a }}\end{array}$ & $\begin{array}{c}\mathrm{Global} \mathrm{Oceans,} \\
\mathrm{Tg} \mathrm{CO}_{2} \mathrm{yr}^{-1}\end{array}$ \\
\hline China (CH) & $856 \pm 69$ & $2553 \pm 638$ & $294 \pm 147$ & $693 \pm 520$ & - \\
Korea (KR) & $43 \pm 3$ & $335 \pm 84$ & $1 \pm 0.7$ & $20 \pm 15$ & - \\
Japan (JP) & $30 \pm 1$ & $813 \pm 203$ & $6 \pm 3$ & $41 \pm 31$ & - \\
Southeast Asia (SEA) & $419 \pm 189$ & $608 \pm 274$ & $1320 \pm 660$ & $23 \pm 17$ & - \\
Boreal Asia (BA) & - & - & $197 \pm 99$ & $360 \pm 270$ & - \\
Rest of world (ROW) & $1800 \pm 900$ & $17137 \pm 4741$ & $6467 \pm 3331$ & $698 \pm 524$ & $-8050 \pm-8050$ \\
\hline
\end{tabular}

${ }^{\mathrm{a}}$ Net flux for March 2001. 


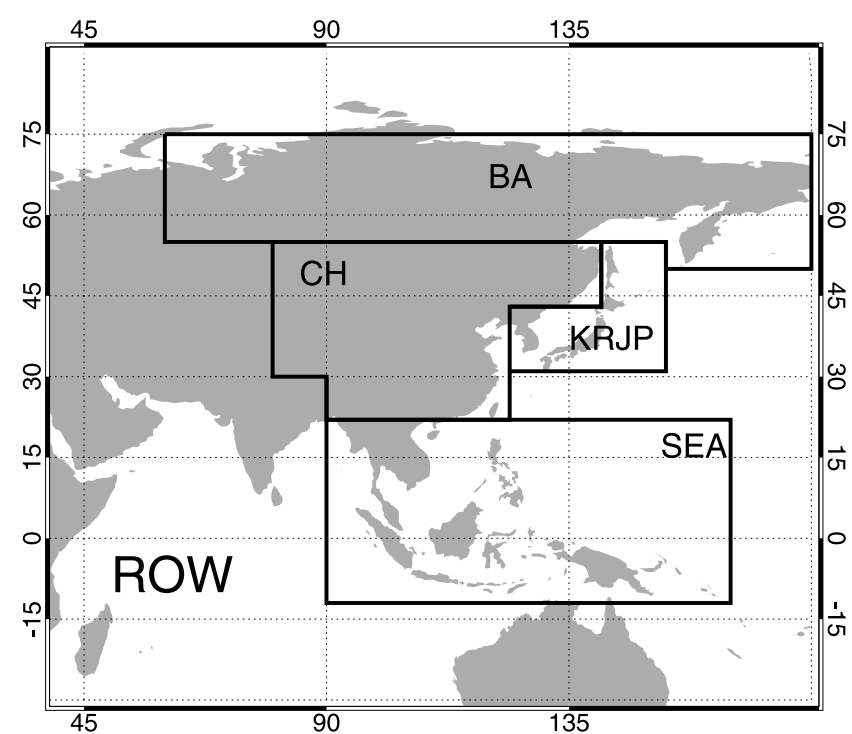

Figure 4. Source regions for tagged $\mathrm{CO}$ and $\mathrm{CO}_{2}$ simulations. See Tables 2 and 3 for flux estimates.

[23] The maximum a posteriori solution [Rodgers, 1976] is given by

$$
\begin{gathered}
\hat{\mathbf{x}}=\mathbf{x}_{a}+\left(\mathbf{K}^{\mathrm{T}} \mathbf{S}_{\Sigma}^{-1} \mathbf{K}+\mathbf{S}_{a}^{-1}\right)^{-1} \mathbf{K}^{\mathrm{T}} \mathbf{S}_{\Sigma}^{-1}\left(\mathbf{y}-\mathbf{K} \mathbf{x}_{a}\right) \\
\hat{\mathbf{S}}=\left(\mathbf{K}^{\mathrm{T}} \mathbf{S}_{\Sigma}^{-1} \mathbf{K}+\mathbf{S}_{a}^{-1}\right)^{-1}
\end{gathered}
$$

where $\mathbf{S}_{a}$ is the a priori error covariance matrix, $\hat{\mathbf{x}}$ is the optimized a posteriori state vector, $\hat{\mathbf{S}}$ is the a posteriori error covariance matrix describing the error associated with $\hat{\mathbf{x}}$, and other variables are as defined previously. Source and observation $\mathrm{CO}_{2}: \mathrm{CO}$ error correlations, as derived in section 2 , are implemented in the inversion as off-diagonal terms in $\mathbf{S}_{a}$ and $\mathbf{S}_{\Sigma}$, respectively.

[24] Inverse modeling using Bayesian synthesis generates artificially small a posteriori errors, due to the assumption that observational errors are random, Gaussian, representatively sampled by the observations, and described accurately by its covariance [Heald et al., 2004]. Here we use the a posteriori errors as a qualitative measure of the constraint provided by the $\mathrm{CO}_{2}: \mathrm{CO}$ error correlations.

\subsection{Error Variance and Covariance Specification}

[25] Error variance and covariance information is included in the inversion as diagonal and off-diagonal terms in $\mathbf{S}_{a}$ and $\mathbf{S}_{\Sigma}$, respectively. We specify a priori emission error variances for Asia following Streets et al. [2003]. We assign an uncertainty of $25 \%$ on the global source of $\mathrm{CO}$ from the oxidation of $\mathrm{CH}_{4}$ and biogenic NMVOCs [Palmer et al., 2003], and further assume flux uncertainties for $\mathrm{CO}_{2}$ from the ocean and terrestrial biosphere of $100 \%$ and $75 \%$, respectively.

[26] Observation error variances are quantified using the mean statistics of the relative difference between the observed and model concentrations as a function of altitude and latitude [Palmer et al., 2003; Heald et al., 2004]. The mean bias between the model and observed concentration is assumed to reflect errors in model fluxes to be retrieved by the inversion, while the standard deviation about the mean bias (residual relative error, RRE) is assumed to reflect total observation error. RRE values for CO are typically $20-30 \%$ [Palmer et al., 2003]. Similar analysis for $\mathrm{CO}_{2}$ shows RRE values of $1-2 \%$, with little variability as a function of altitude or latitude. The observation error variance for an individual observation $\mathrm{y}_{i}$ is given by $\left(\mathrm{RRE} \times \mathrm{y}_{i}\right)^{2}$.

[27] Observed correlations between $\mathrm{CO}_{2}$ and $\mathrm{CO}$ concentrations imply corresponding observation error correlations (section 2 and Figure 2), which we use to specify the offdiagonal elements in $\mathbf{S}_{\Sigma}$. Correlations in $\mathrm{CO}$ and $\mathrm{CO}_{2}$ emission errors provide similar information to construct the off-diagonal elements of $\mathbf{S}_{a}$ (section 2). These $\mathrm{CO}_{2}: \mathrm{CO}$ error correlation coefficients, $r$, are included as off-diagonal elements in $\mathbf{S}_{\Sigma}$ and $\mathbf{S}_{a}$ following

$$
s_{i, j}=r_{i, j} \sqrt{s}_{i, i} \sqrt{s}_{j, j} .
$$

We neglect the spatial correlations of observations as previous work for $\mathrm{CO}$ during TRACE-P has shown that it decays on a length scale of $150 \mathrm{~km}$ [Jones et al., 2003; Heald et al., 2004], which is short relative to the $2^{\circ} \times 2.5^{\circ}$ grid over which the observations are sampled here.

\section{Inversion Results}

\subsection{Best-Case Estimate}

[28] Figure 5 shows results for our best-case inversion of $\mathrm{CO}$ and $\mathrm{CO}_{2}$ fluxes that uses the state vector defined in section 3, and the $\mathrm{CO}_{2}: \mathrm{CO}$ error correlations derived in section 2. The results for $\mathrm{CO}$ are generally the same as those presented by Palmer et al. [2003], including a 72\% increase in the anthropogenic source from China but the $45 \%$ decrease in Southeast Asia obtained here is less than the $60 \%$ decrease inferred from using only TRACE-P CO data, and is more consistent with the constraints from the MOPITT data [Heald et al., 2004]. The CO source from Chinese biomass burning is weakly negative but is not significantly different from zero, given that $\hat{\mathbf{S}}$ underestimates actual a posteriori errors.

[29] A posteriori emissions of $\mathrm{CO}_{2}$ show a $18 \%$ decrease in Chinese anthropogenic sources and a $10 \%$ increase in sources from Korea and Japan. The a posteriori decrease (increase) in Chinese anthropogenic $\mathrm{CO}_{2}(\mathrm{CO})$ source estimates implies an overestimate of sources with high $\mathrm{CO}_{2}: \mathrm{CO}$ signatures, and a missing source with a low $\mathrm{CO}_{2}: \mathrm{CO}$ signature, e.g., which could be contributed by small heavily polluting power plants [Tan et al., 2004] or burning of domestic coal and biofuels [Carmichael et al., 2003]. There is also a 95\% reduction in the net Chinese biospheric $\mathrm{CO}_{2}$ source for March 2001 relative to the CASA model, consistent with the results of Suntharalingam et al. [2004], and a $10 \%$ increase in $\mathrm{CO}_{2}$ from the boreal Asia biosphere.

\subsection{Sensitivity Studies}

[30] Here we assess the added value of $\mathrm{CO}_{2}: \mathrm{CO}$ error correlations by comparing our best-case estimates with sensitivity calculations using modified correlations, i.e., modified off-diagonal terms in $\mathbf{S}_{\Sigma}$ and $\mathbf{S}_{a}$. The uncorrelated inversion (best-case inversion but with off-diagonal terms 

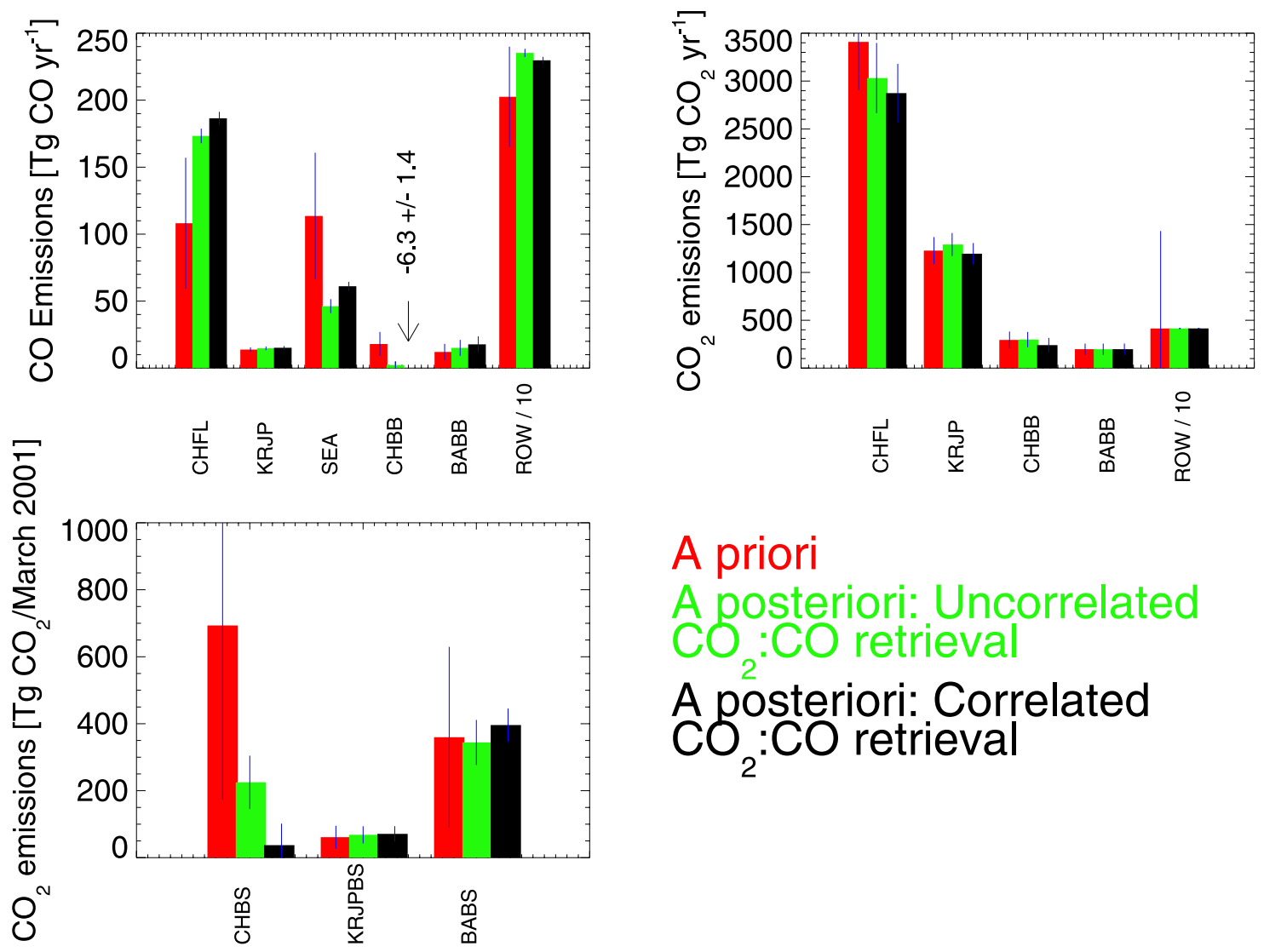

Figure 5. A priori (red), uncorrelated a posteriori (green), and best-case a posteriori (black) CO and $\mathrm{CO}_{2}$ flux estimates. The vertical lines superimposed on each estimate denotes the $1 \sigma$ uncertainty.

set to zero) estimates independently the optimal flux estimates of $\mathrm{CO}$ and $\mathrm{CO}_{2}$ (Figure 5). A posteriori emissions of $\mathrm{CO}$ are within a few percent of the best case inversion analysis, with the exception of biomass burning from Southeast Asia, as described above. A posteriori CO estimates are tightly constrained by the $\mathrm{CO}$ concentration data and are largely insensitive to changes in $\mathbf{S}_{a}$ and $\mathbf{S}_{\Sigma}$ introduced by the $\mathrm{CO}_{2}: \mathrm{CO}$ error covariances. In the case of the Southeast Asian source, transport to the TRACE-P sampling region involved lifting to the free troposphere by convection and warm conveyor belts [Liu et al., 2003]. Consideration of the $\mathrm{CO}_{2}$ : $\mathrm{CO}$ correlations in other geopolitical regions appears to help reduce the model transport errors associated with the Southeast Asian source, resulting in better agreement with the $\mathrm{CO}$ inversions that use the much denser MOPITT data [Heald et al., 2004].

[31] Including $\mathrm{CO}_{2}: \mathrm{CO}$ correlations further reduces the Chinese biospheric flux by $80 \%$, while KRJPBS and BABS estimates are not significantly different from the uncorrelated inverse analyses. Examination of the a posteriori correlation matrix (normalized $\hat{\mathbf{S}}$ ) shows a particularly strong anticorrelation $(-0.8)$ between $\mathrm{CO}_{2}$ fluxes from anthropogenic and biospheric sources. Consideration of the $\mathrm{CO}_{2}: \mathrm{CO}$ error correlation in the inversion facilitates the separation of these two sources by reducing the correlation between biospheric and anthropogenic sources. Figure 6 illustrates for China the strong anticorrelation between CHFL and CHBS remains until source or observation $\mathrm{CO}_{2}: \mathrm{CO}$ error

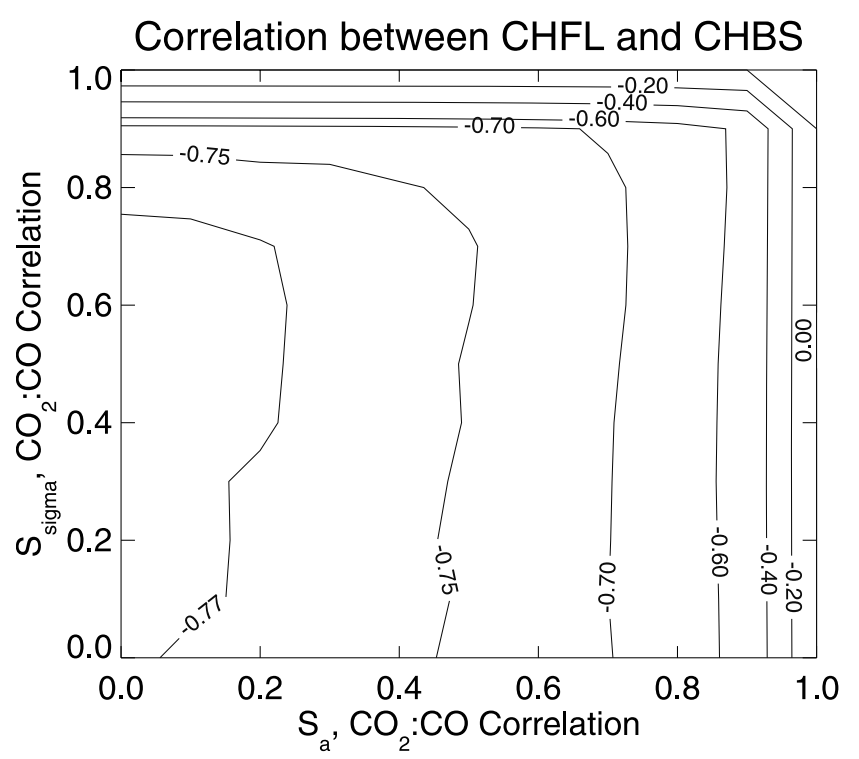

Figure 6. Sensitivity of the a posteriori correlation between Chinese anthropogenic (CHFL) and biospheric (CHBS) $\mathrm{CO}_{2}$ flux estimates to the source $\left(\mathbf{S}_{a}\right)$ and observation $\left(\mathbf{S}_{\Sigma}\right) \mathrm{CO}_{2}: \mathrm{CO}$ error correlations. 

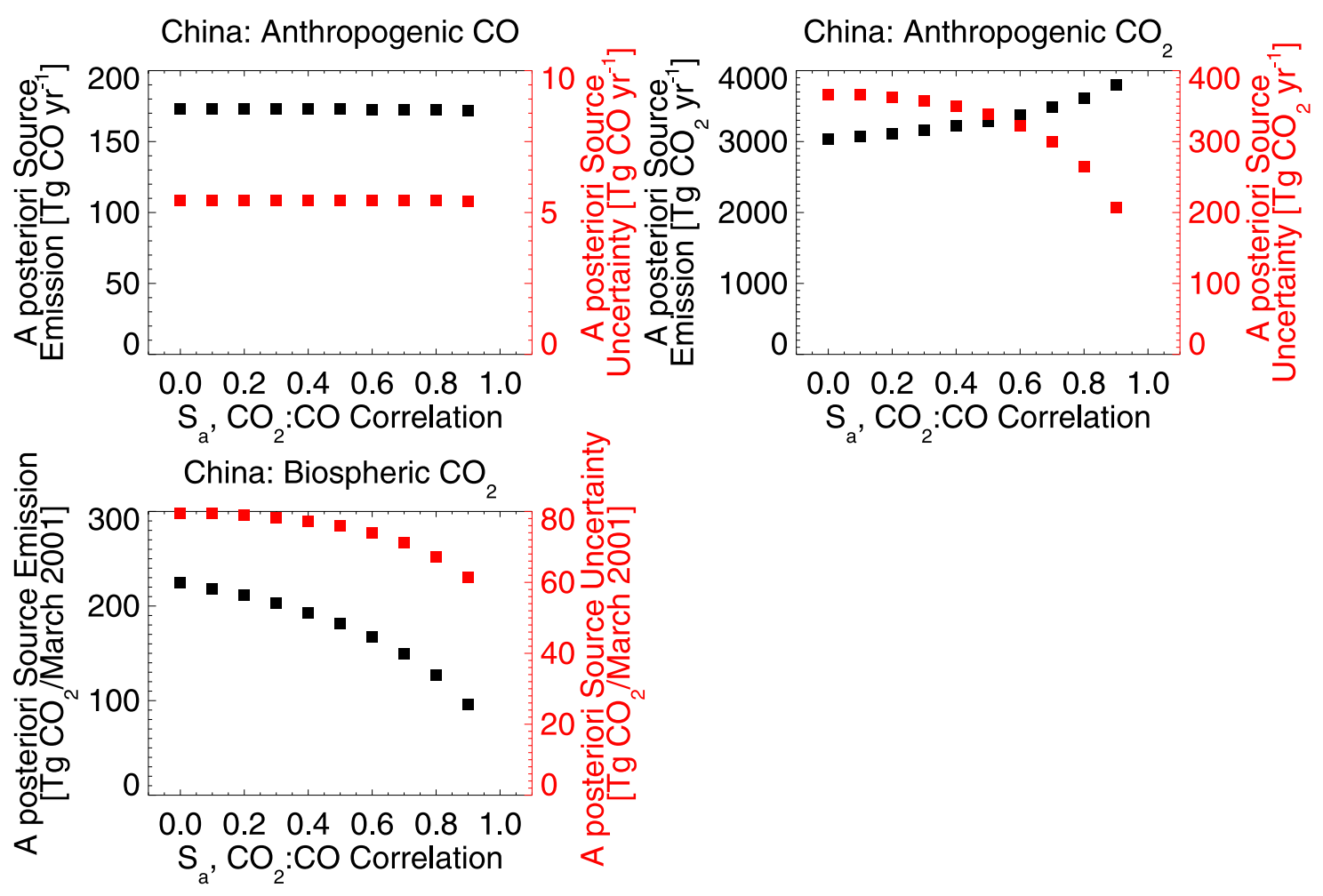

Figure 7. Sensitivity of a posteriori Chinese anthropogenic source estimates and their uncertainties to the source $\mathrm{CO}_{2}: \mathrm{CO}$ error correlation $\left(\mathbf{S}_{a}\right)$.

correlations are greater than $0.7-0.8$, after which it drops rapidly to zero. The source $\mathrm{CO}_{2}: \mathrm{CO}$ error correlation is the more effective constraint for separating biospheric and anthropogenic sources but as discussed earlier this error correlation is weak. Our best estimate, which uses both source and observation $\mathrm{CO}_{2}: \mathrm{CO}$ error correlations, leads to a CHFL:CHBS correlation 10\% less than the uncorrelated inversion.

[32] Figures 7 and 8 illustrate the sensitivity of a posteriori Chinese fluxes to the strengths of the source and observation $\mathrm{CO}_{2}: \mathrm{CO}$ error correlations. Source $\mathrm{CO}_{2}: \mathrm{CO}$ error correlation (Figure 7) provides little improvement in a posteriori $\mathrm{CO}$ source estimates, since $\mathrm{CO}$ atmospheric concentration signals are much stronger than for $\mathrm{CO}_{2}$ and the transport from China to the TRACE-P sampling region is principally by boundary layer advection [Liu et al., 2003] which has low transport error. Anthropogenic and biospheric $\mathrm{CO}_{2}$ flux estimates are statistically significantly different from the uncorrelated inversion where the source $\mathrm{CO}_{2}$ : $\mathrm{CO}$ error correlation is greater than 0.5. However, with the emission uncertainty for $\mathrm{CO}$ contributed mostly by emission factor [Streets et al., 2003] the source $\mathrm{CO}_{2}: \mathrm{CO}$ error correlation is much less than 0.5 (Table 1). We conclude that the source $\mathrm{CO}_{2}$ : $\mathrm{CO}$ error correlation is unlikely to offer much benefit for joint $\mathrm{CO}_{2}: \mathrm{CO}$ inversions. In contrast, accounting for forward model error $\mathrm{CO}_{2}$ :CO correlation (i.e., off-diagonal terms of $\mathbf{S}_{\Sigma}$ ) effectively reduces the uncertainty of the observations (Figure 8). The magnitude of a posteriori $\mathrm{CO}$ estimates increases slightly with increasing $\mathrm{CO}_{2}: \mathrm{CO}$ error correlation, with the associated uncertainties decreasing. This reduction in
$\mathrm{CO}$ emission uncertainty is observed only with changes in $\mathbf{S}_{\Sigma}$ because the observation uncertainties dominate the calculation of $\hat{\mathbf{S}}$ (equation (4)). The magnitude of the Chinese biospheric $\mathrm{CO}_{2}$ flux reduces as the observation error $\mathrm{CO}_{2}: \mathrm{CO}$ correlation increases and is a $\mathrm{CO}_{2}$ sink at correlations greater than 0.8 . The magnitude of the a posteriori Chinese anthropogenic $\mathrm{CO}_{2}$ estimate is not significantly affected by increasing the observation error $\mathrm{CO}_{2}: \mathrm{CO}$ correlation. Separation of the biospheric and anthropogenic $\mathrm{CO}_{2}$ sources, indicated by the a posteriori correlation matrix (Figure 6), occurs at correlations coefficients $>0.7$, similar to observed $\mathrm{CO}_{2}$ : $\mathrm{CO}$ correlation (Figure 2). The importance of the $\mathrm{CO}_{2}: \mathrm{CO}$ error correlations in the TRACE-P inverse problem lies in their role of reducing model transport error and subsequently reducing uncertainty on a posteriori $\mathrm{CO}_{2}$ flux estimates.

\section{Closing Remarks}

[33] Accurately quantifying $\mathrm{CO}_{2}$ exchanges with the terrestrial biosphere represents an important challenge for understanding the global carbon cycle. A standard method has been to use inverse models constrained with atmospheric observations of $\mathrm{CO}_{2}$, and occasionally $\mathrm{CO}_{2}$ isotopes. Strong observed correlations between $\mathrm{CO}_{2}$ and $\mathrm{CO}$ in atmospheric data, as well as $\mathrm{CO}_{2}: \mathrm{CO}$ correlations in combustion sources, suggest that a joint $\mathrm{CO}_{2}: \mathrm{CO}$ inversion might provide information to improve the separation of combustion and biospheric $\mathrm{CO}_{2}$ surface flux estimates. We showed here that such an inversion, using concurrent observations of $\mathrm{CO}_{2}$ and $\mathrm{CO}$ in Asian outflow from the 

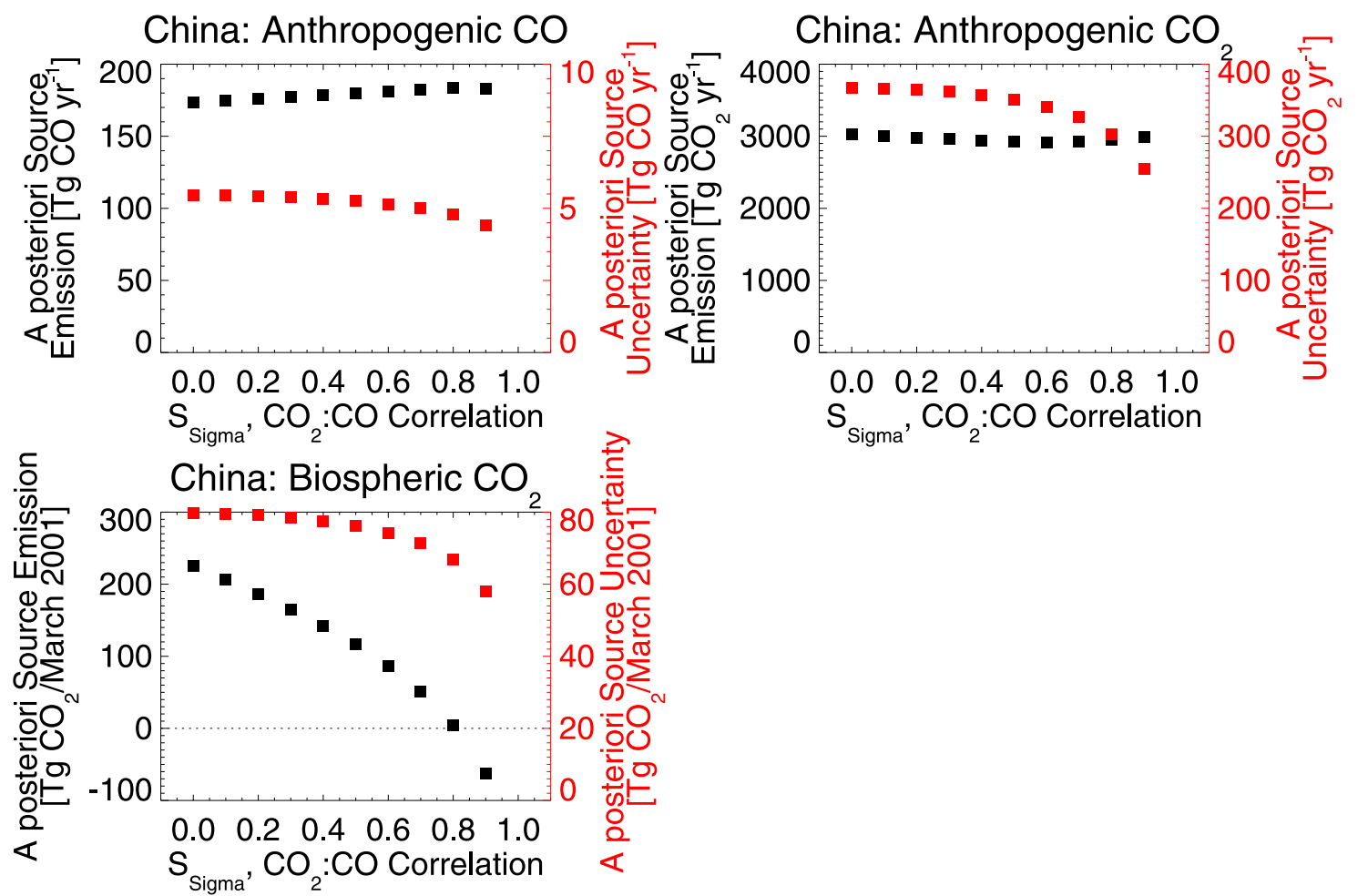

Figure 8. Sensitivity of a posteriori Chinese anthropogenic source estimates and their uncertainties to the observation $\mathrm{CO}_{2}: \mathrm{CO}$ error correlation $\left(\mathbf{S}_{\Sigma}\right)$.

TRACE-P aircraft campaign in Spring 2001, does indeed provide useful additional constraints for improving a posteriori $\mathrm{CO}_{2}$ regional flux estimates.

[34] Observed correlations between $\mathrm{CO}_{2}$ and $\mathrm{CO}$ concentrations in atmospheric data imply a corresponding correlation in source-receptor relationships, and therefore in the forward model errors for the inversion. Mathematically, they can be used to estimate off-diagonal terms in the observation error covariance matrix $\left(\mathbf{S}_{\Sigma}\right)$ of a joint $\mathrm{CO}_{2}: \mathrm{CO}$ inversion. Observed $\mathrm{CO}_{2}: \mathrm{CO}$ correlation coefficients during TRACE-P are generally larger than 0.7 [Suntharalingam et al., 2004; Takegawa et al., 2004] and enable significant improvement of a posteriori flux estimates. $\mathrm{CO}_{2}: \mathrm{CO}$ correlations may be different for other regions and during other seasons.

[35] Correlation between $\mathrm{CO}_{2}$ and $\mathrm{CO}$ combustion sources in a priori estimates could also provide constraints to the joint inversion. We used a Monte Carlo approach to quantify the resulting $\mathrm{CO}_{2}: \mathrm{CO}$ source error correlations in individual Asian countries on the basis of uncertainties in activity rates and emission factors for individual energy sectors and source regions reported by the east Asia emission inventory of Streets et al. [2003]. We find that these correlation coefficients are weak $(r<0.2)$ because $\mathrm{CO}$ emission factors are the largest contribution to the overall uncertainty. Significant improvements in a posteriori $\mathrm{CO}_{2}$ and $\mathrm{CO}$ would require correlation coefficients $>0.7$ but these would require unrealistic uncertainties in activity rates.

[36] We find that the benefit of including $\mathrm{CO}_{2}: \mathrm{CO}$ error correlations in joint $\mathrm{CO}_{2}: \mathrm{CO}$ inversions is mainly for improving retrievals of $\mathrm{CO}_{2}$ surface fluxes, not $\mathrm{CO}$ sources. Atmospheric variability of $\mathrm{CO}$ is far greater than that of $\mathrm{CO}_{2}$, and separation of biospheric and combustion terms is not an issue, so that information on $\mathrm{CO}_{2}$ has little benefit for the $\mathrm{CO}$ source inversion.

[37] Satellite observations of $\mathrm{CO}_{2}$ have the potential to improve quantitative understanding of the global carbon cycle [e.g., Pak and Prather, 2001; Rayner and O'Brien, 2001]. Our work shows that this potential can be enhanced by exploiting correlations with concurrent satellite observations of $\mathrm{CO}$, where $\mathrm{CO}$ information may be coretrieved from the measured spectra of one instrument (e.g., SCIAMACHY and AIRS), retrieved from another instrument aboard the same satellite platform, or taken from an instrument in the same orbit (e.g., OCO and TES).

\section{Appendix A: Forward Model}

[38] The GEOS-CHEM version used here (6.01, http:// www-as.harvard.edu/chemistry/trop/geos/index.html) has a horizontal resolution of $2^{\circ} \times 2.5^{\circ}$, with 48 vertical levels ranging from the surface to the mesosphere, 20 of which are below $12 \mathrm{~km}$. The model is driven by GEOS-3 assimilated meteorology data from the Global Modeling and Assimilation Office GCM based at NASA Goddard. The 3-D meteorological data are updated every 6 hours, and the mixing depths and surface fields are updated every 3 hours.

[39] The $\mathrm{CO}$ and $\mathrm{CO}_{2}$ simulation are as described by Palmer et al. [2003] and Suntharalingam et al. [2004], respectively. The main sink for $\mathrm{CO}$ is oxidation by $\mathrm{OH}$, 
leading to a lifetime of a few months. We prescribe global monthly mean $\mathrm{OH}$ fields calculated from a full chemistry model simulation (GEOS-CHEM v4.33) and consistent with observational constraints [Prinn et al., 2001]. The CO sink has little effect for the inversion of TRACE-P measurements, which are only a few days downwind of the Asian sources. The impact of the $\mathrm{OH}$ sink on the $\mathrm{CO}$ background is effectively taken into account by the adjustment of the ROW CO source [Palmer et al., 2003]. Suntharalingam et al. [2005] showed that not properly accounting for reduced carbon species $\left(\mathrm{CO}, \mathrm{CH}_{4}\right.$ and NMVOCs) in $\mathrm{CO}_{2}$ inversion analyses can significantly bias a posteriori flux estimates. This bias arises for two reasons: not accounting for the 3-D production of $\mathrm{CO}_{2}$ from the oxidation of reduced carbon species and neglecting that reduced carbon species are often included in bottom-up combustion and biospheric $\mathrm{CO}_{2}$ flux inventories. Air masses sampled during TRACE-P are relatively fresh and so the oxidation effect will only affect observations that sample the background atmosphere. The Streets et al. [2003] combustion emission inventory only accounts for direct emissions of $\mathrm{CO}_{2}$, however the terrestrial biospheric fluxes from CASA do account for reduced carbon species.

[40] The Jacobian matrix for the inversion is constructed by transporting separately $\mathrm{CO}$ and $\mathrm{CO}_{2}$ from individual sources describing the state vector. This required initialization of the corresponding "tagged tracers." The CO simulation is initialized in January 2000 and integrated for 16 months (through April 2001). The 14 months prior to TRACE-P effectively remove the influence of initial conditions. In the case of $\mathrm{CO}_{2}$, we adopt the model initialization approach previously used by Xiao et al. [2004] for $\mathrm{CH}_{4}$ in GEOS-CHEM. We use the total $\mathrm{CO}_{2}$ simulation to define a background $\mathrm{CO}_{2}$ tracer as the $\mathrm{CO}_{2}$ present in the atmosphere on 1 January 2001. The background tracer has no surface fluxes after January 2001 and is allowed to mix. The other tagged tracers are initialized with zero concentration on 1 January 2001. Their concentrations evolve over the course of the simulation as a result of surface fluxes. We also included an additional initialization to the $\mathrm{CO}_{2}$ simulation to correct the model bias introduced by not accounting for the net uptake of $\mathrm{CO}_{2}$ by the land biosphere. We make this correction by comparing the 20th percentile (assumed to represent the $\mathrm{CO}_{2}$ background) in the model and observed $\mathrm{CO}_{2}$ concentration data (east of $150^{\circ} \mathrm{W}$ ) as a function of latitude ( $5^{\circ}$ increments), and remove it from the model values. The corresponding model bias ranges from 4 to $5 \mathrm{ppm}$ and is consistent with the values calculated using GLOBALVIEW $\mathrm{CO}_{2}$ data [Suntharalingam et al., 2004].

[41] Acknowledgment. This work was supported by the NASA and NOAA carbon cycle programs.

\section{References}

Allen, D., K. Pickering, and M. Fox-Rabinnovitz (2004), Evaluation of pollutant outflow and CO sources during TRACE-P using model-calculated, aircraft-based, and Measurements of Pollution in the Troposphere (MOPITT)-derived CO concentrations, J. Geophys. Res., 109, D15S03, doi:10.1029/2003JD004250.
Andreae, M. O., and P. Merlet (2001), Emission of trace gases and aerosols from biomass burning, Global Biogeochem. Cycles, 15, 955-966.

Blake, N. C., et al. (2003), NMHCs and halocarbons in Asian continental ouflow during TRACE-P: Comparison to PEM-West B, J. Geophys. Res., 108(D20), 8806, doi:10.1029/2002JD003367.

Bousquet, P., P. Ciais, P. Peylin, M. Ramonet, and P. Monfray (1999), Inverse modeling of annual atmospheric $\mathrm{CO}_{2}$ sources and sink: 1 . Method and control inversion, J. Geophys. Res., 104, 26,161-26,178. Carmichael, G. R., et al. (2003), Evaluating regional emission estimates using TRACE-P observations, J. Geophys. Res., 108(D21), 8810, doi:10.1029/2002JD003116.

Ciais, P., P. P. Tans, M. Trolier, J. W. C. White, and R. J. Francey (1995), A large Northern Hemisphere terrestrial $\mathrm{CO}_{2}$ sink indicated by the ${ }^{13} \mathrm{C} /{ }^{12} \mathrm{C}$ ratio of atmospheric $\mathrm{CO}_{2}$, Science, 269, 1098-1102.

Duncan, B. N., R. V. Martin, A. C. Staudt, R. Yevich, and J. A. Logan (2003), Interannual and seasonal variability of biomass burning emissions constrained by satellite observations, J. Geophys. Res., 108(D2), 4100, doi:10.1029/2002JD002378.

Enting, I. G., C. M. Trudinger, and R. J. Francey (1995), A synthesis inversion of the concentration and delta-C-13 of atmospheric $\mathrm{CO}_{2}$, Tellus, Ser. B, 47, 35-52.

Fuelberg, H. E., et al. (2003), Meteorological conditions and transport pathways during Transport and Chemical Evolution over the Pacific (TRACE-P) experiment, J. Geophys. Res., 108(D20), 8782, doi:10.1029/2002JD003092.

Gilliland, A. B., R. L. Dennis, S. J. Roselle, and T. E. Pierce (2003), Seasonal $\mathrm{NH}_{3}$ emission estimates for the eastern United States based on ammonium wet concentrations and an inverse modeling method, J. Geophys. Res., 108(D15), 4477, doi:10.1029/2002JD003063.

Heald, C. L., D. J. Jacob, P. I. Palmer, M. J. Evans, G. W. Sachse, H. B. Singh, and D. R. Blake (2003), Biomass burning emission inventory with daily resolution: Application to aircraft observations of Asian outflow, J. Geophys. Res., 108(D21), 8811, doi:10.1029/2002JD003082.

Heald, C. L., et al. (2004), Comparative inverse analysis of satellite (MOPITT) and aircraft (TRACE-P) observations to estimate Asian sources of carbon monoxide, J. Geophys. Res., 109, D23306, doi:10.1029/ 2004JD005185.

Jacob, D. J., et al. (2003), The Tranport and Chemical Evolution over the Pacific (TRACE-P) mission: Design, execution and overview of results, J. Geophys. Res., 108(D20), 9000, doi:10.1029/2002JD003276.

Jones, D. B. A., K. W. Bowman, P. I. Palmer, J. R. Worden, D. J. Jacob, R. N. Hoffman, I. Bey, and R. M. Yantosca (2003), Potential of observations from the Tropospheric Emission Spectrometer to constrain continental sources of carbon monoxide, J. Geophys. Res., 108(D24), 4789, doi:10.1029/ 2003JD003702.

Liu, H., D. J. Jacob, I. Bey, R. M. Yantosca, B. N. Duncan, and G. W. Sachse (2003), Transport pathways for Asian combustion outflow over the Pacific: Interannual and seasonal variations, J. Geophys. Res., 108(D20), 8786, doi:10.1029/2002JD003102.

Pak, B. C., and M. J. Prather (2001), $\mathrm{CO}_{2}$ source inversions using satellite observations of the upper troposphere, Geophys. Res. Lett., 28, 45714574.

Palmer, P. I., D. J. Jacob, D. J. A. Jones, C. L. Heald, R. M. Yantosca, J. A. Logan, G. W. Sachse, and D. G. Streets (2003), Inverting for emissions of carbon monoxide from Asia using aircraft observations over the western Pacific, J. Geophys. Res., 108(D21), 8828, doi:10.1029/2003JD003397.

Prinn, R. G., et al. (2001), Evidence for substantial variation of atmospheric hydroxyl radicals in the past two decades, Science, 292, 1882-1888.

Randerson, J. T., M. V. Thompson, T. J. Conway, I. Y. Fung, and C. B. Field (1997), The contribution of terrestrial sources and sinks to trends in the seasonal cycle of atmospheric carbon dioxide, Global Biogeochem. Cycles, 11, 535-560.

Rayner, P. J., and D. M. O'Brien (2001), The utlility of remotely sensed $\mathrm{CO}_{2}$ concentration data in surface source inversions, Geophys. Res. Lett., $28,175-178$.

Rodgers, C. D. (1976), Retrieval of atmospheric temperature and composition from remote measurements of thermal radiation, Rev. Geophys., 14, $609-624$.

Sachse, G. W., G. F. Hill, L. O. Wade, and M. G. Perry (1987), Fastresponse, high-precision carbon monoxide sensor using a tunable diode laser absorption technique, J. Geophys. Res., 92, 2071-2081.

Streets, D. G., et al. (2003), An inventory of gaseous and primary aerosol emissions in Asia in the year 2000, J. Geophys. Res., 108(D21), 8809, doi:10.1029/2002JD003093.

Suntharalingam, P., et al. (2004), Improved quantification of Chinese carbon fluxes using $\mathrm{CO}_{2} / \mathrm{CO}$ correlations in Asian outflow, J. Geophys. Res., 109, D18S18, doi:10.1029/2003JD004362.

Suntharalingam, P., J. T. Randerson, N. Krakauer, D. J. Jacob, and J. A. Logan (2005), The influence of reduced carbon emissions and oxidation 
on the distribution of atmospheric $\mathrm{CO}_{2}$ : Implications for inversion analysis, Global Biogeochem. Cycles, 19, GB4003, doi:10.1029/ 2005 GB002466.

Takahashi, T. (1999), Net air-sea $\mathrm{co}_{2}$ flux over the global oceans, in Proceedings of 2nd International Symposium $\mathrm{CO}_{2}$ in the Oceans: CGER 1037, pp. 9-15, Natl. Inst. for Environ. Stud., Tsukuba, Japan.

Takegawa, N., et al. (2004), Removal of $\mathrm{NO}_{x}$ and $\mathrm{NO}_{y}$ in Asian outflow plumes: Aircraft measurements over western Pacific in January 2002, J. Geophys. Res., 109, D23S04, doi:10.1029/2004JD004866.

Tan, Q., W. L. Chameides, D. Streets, T. Wang, J. Wu, M. Bergin, and J. Woo (2004), An evaluaton of TRACE-P emission inventories from China using a regional model and chemical measurements, J. Geophys. Res., 109, D22305, doi:10.1029/2004JD005071.

Vay, S. A., et al. (2003), Influence of regional-scale athropogenic emissions on $\mathrm{CO}_{2}$ distributions over the western North Pacific, J. Geophys. Res., 108(D20), 8801, doi:10.1029/2002JD003094.

Xiao, Y., J. S. W. D. J. Jacob, J. A. Logan, P. I. Palmer, P. Suntharalingam, R. M. Yantosca, G. W. Sachse, D. R. Blake, and D. G. Streets (2004), Constraints on Asian and European sources of methane from $\mathrm{CH}_{4}-\mathrm{C}_{2} \mathrm{H}_{6}$ -
CO correlations in Asian outflow, J. Geophys. Res., 109, D15S16, doi:10.1029/2003JD004475.

Q. Fu, Shanghai Environmental Monitoring Center, 1 Nan Dan Road, Shanghai 200030, China.

D. J. Jacob and P. Suntharalingam, Division of Engineering and Applied Sciences, Harvard University, 29 Oxford Street, Cambridge, MA 02138, USA.

D. B. A. Jones, Department of Physics, University of Toronto, 60 St. George Street, Toronto, ON, Canada M5S 1A7.

P. I. Palmer, School of Earth and Environment, University of Leeds, Leeds LS2 9JT, UK. (pip@env.leeds.ac.uk)

G. W. Sachse and S. A. Vay, NASA Langley Research Center, 100 NASA Road Hampton, VA 23681, USA.

D. G. Streets, Argonne National Laboratory, 9700 South Cass Avenue, Argonne, IL 60439, USA. 